\title{
A EXTENSÃO COMO EXPRESSÃO DA RESPONSABILIDADE SOCIAL UNIVESITÁRIA
}

\begin{abstract}
EXTENSION AS EXPRESSION OF SOCIAL
RESPONSIBILITY FOR HIGHER EDUCATION

LA EXTENSIÓN COMO EXPRESIÓN DE LA

RESPONSABILIDAD SOCIAL UNIVERSITARIA

\section{Ricardo Antonio De Marco ${ }^{1}$ \\ Dirleia Fanfa Sarmento ${ }^{2}$ \\ Jardelino Menegat ${ }^{3}$}

RESUMO

O Sistema Nacional de Avaliação da Educação Superior de 2004, no seu Eixo 2, Desenvolvimento Institucional e respectivas Dimensões 1 e 3: Missão e o Plano de Desenvolvimento Institucional (PDI) e a Responsabilidade Social da Instituição, destaca a necessidade das Universidades incorporarem em suas atividades de ensino, pesquisa e extensão práticas que evidenciem sua implicação positiva no Desenvolvimento Social. Nesse sentido, este artigo pretende avaliar como a prática da extensão universitária contribui para a consolidação da Responsabilidade Social Universitária. Utilizou-se como método a pesquisa descritiva e análise documental que verificou os documentos institucionais da Universidade do Oeste de Santa Catarina: missão, visão e valores; Plano de Desenvolvimento Institucional e o projeto de extensão Universidade da Melhor Idade de Chapecó (UMIC); e o Sistema Nacional de Avaliação da Educação Superior. A partir dessa inferência, foi possível perceber que a UNOESC, em seus princípios constitutivos e documentos oficiais, valoriza a formação cidadã orientada para a inserção social. Constatou-se que a consolidação da RSU passa necessariamente pelo olhar atento da gestão aos princípios da indissociabilidade entre o ensino, pesquisa e extensão, elementos constitutivos e findos das universidades, que quando não executados adequadamente, contrariam e violam o preceito legal; que projetos de Extensão de cunho inter e transdisciplinar, como a UMIC, apresentam forte contribuição para a consolidação da RSU; paralelamente, restou evidente que isoladamente projetos de Extensão como a UMIC não atingem na plenitude o compromisso social das Universidades, sugerindo que a indissociabilidade esteja presente com a incorporação de ações que promovam Desenvolvimento Social.
\end{abstract}

PALAVRAS-CHAVE: Responsabilidade social universitária. Extensão. Indissociabilidade.

\begin{abstract}
The National System of Higher Education Assessment 2004 in Axis 2, Institutional Development and its dimensions 1 and 3: Mission and Institutional Development Plan (IDP) and the Social Responsibility of the institution highlights the need for universities to incorporate in their activities teaching, research and extension practices that demonstrate their positive involvement in social development. In this sense, this article aims to evaluate the practice of university extension contributes to the consolidation of University Social Responsibility. was used as a method descriptive research and documentary analysis found that the institutional documents of

\footnotetext{
${ }^{1}$ Doutorando em Educação pela UNILASALLE. Mestrado em Administração pela Universidade do Sul de Santa Catarina. E-mail: ricardo.demarco@unoesc.edu.br

${ }^{2}$ Pós-Doutorado em Ciências da Educação pela Universidade do Algarve (Portugal). Pós-doutoramento em Educação, em andamento, pela Universidade Federal Fluminense. Doutorado em Educação pela Universidade Federal do Rio Grande do Sul. Mestrado em Educação pela Universidade do Vale do Rio dos Sinos. E-mail: dirleia.sarmento@unilasalle.edu.br.

${ }^{3}$ Doutorando em Educação pela UNILASALLE, Doutorando em Administración de Empresas, pela Universidad de La Empresa (Montevideo-Uruguay). Mestrado em Gestão do Conhecimento e Tecnologia da Informação, pela Universidade Católica de Brasília. E-mail: jmenegat@terra.com.br
}

Submetido em: 02/02/2016 - Aceito em: 20/04/2016.

\begin{tabular}{l|l|l|l|l|l|l} 
(C) Rev. Inter. Educ. Sup. & Campinas, SP & v.2 & n.1 & p.191-213 & jan./abr. 2016 & ISSN 2446-9424
\end{tabular} 
the University of the West of Santa Catarina: mission, vision and values; Institutional Development Plan and the extension project of the University of Chapecó Best Age (UMIC); and the National System of Higher Education Evaluation. From this inference, it was revealed that UNOESC in its constitutive principles and official documents value-oriented civic education for social inclusion. It was found that the consolidation of MSW necessarily involves watchful eye of management to the principles of indivisibility of teaching, research and extension, components and ended the universities, which when not properly executed, counter and violate the legal provision; that inter- and transdisciplinary nature of extension projects, such as UMIC, have strong contribution to the consolidation of MSW; parallel, left clear that isolation Extension projects like UMIC not reach the fullness of the social commitment of universities, suggesting that inseparability is present with the incorporation of actions that promote social development.

KEYWORDS: University social responsibility. Extension. Inseparability

\section{RESUMEN}

El Sistema Nacional de Evaluación de la Educación Superior de 2004, en su Eje 2, Desarrollo Institucional y respectivas Dimensiones 1 y 3: Misión y el Plan de Desarrollo Institucional (PDI) y la Responsabilidad Social de la Institución, destaca la necesidad de que las Universidades incorporen en sus actividades de enseñanza, investigación y extensión prácticas que evidencien su implicación positiva en el Desarrollo Social. En ese sentido, este artículo pretende evaluar cómo la práctica de la extensión universitaria contribuye para la consolidación de la Responsabilidad Social Universitaria. Se ha utilizado como método la investigación descriptiva y el análisis documental que verificó los documentos institucionales de la Universidad del Oeste de Santa Catarina: misión, visión y valores; Plan de Desarrollo Institucional y el proyecto de extensión Universidade da Melhor Idade de Chapecó (UMIC); y el Sistema Nacional de Evaluación de la Educación Superior. A partir de esa inferencia, fue posible percibir que la UNOESC, en sus principios constitutivos y documentos oficiales, valora la formación ciudadana orientada para la inserción social. Se constató que la consolidación de la RSU pasa necesariamente por la mirada atenta de la gestión a los principios de la indisociabilidad entre la enseñanza, investigación y extensión, elementos constitutivos y finales de las universidades, que cuando no ejecutados adecuadamente, contrarían y violan el precepto legal; que proyectos de Extensión de cuño inter y transdisciplinario, como la UMIC, presentan fuerte contribución para la consolidación de la RSU; paralelamente, resultó evidente que aisladamente proyectos de Extensión como la UMIC no atingen en plenitud el compromiso social de las Universidades, sugiriendo que la indisociabilidad esté presente con la incorporación de acciones que promuevan Desarrollo Social.

PALABRAS-CLAVE: Responsabilidad social universitaria. Extensión. Indisociabilidad.

\section{INTRODUÇÃO}

Este texto centra atenção na Extensão Universitária como expressão da Responsabilidade Social Universitária (RSU), considerando a extensão como um processo educativo, promovido pelas universidades para estabelecer uma relação mais direta com outros segmentos da sociedade (PUCCI, 1991; SERRANO, 2013). Desse modo, as Universidades oferecem para a população ações de ensino, pesquisa, extensão como forma de realizar e participar, em conjunto com outros setores da sociedade, de programas e projetos que promovam a superação das desigualdades sociais e o desenvolvimento regional e sociocultural, fator elementar para a inferência Universitária no que tange ao atendimento da RSU, elemento previsto no Sistema Nacional de Avaliação da Educação Superior (SINAES) de 2004, no seu Eixo 2, Desenvolvimento Institucional e respectivas Dimensões 1 e 3: Missão e o Plano de Desenvolvimento Institucional (PDI) e a Responsabilidade Social da Instituição. 
Não obstante, o tripé formado pelo ensino, pesquisa e extensão constitui o eixo fundamental da Universidade brasileira e se constitui elemento indissociável para que os propósitos formativos sejam alcançados. O artigo 207 da Constituição Federal de 1988 dispõe que "as universidades [...] obedecerão ao princípio da indissociabilidade entre ensino, pesquisa e extensão" (BRASIL, 1998). Por este olhar, estão equiparadas as funções associadas ao ensino, pesquisa e extensão nos princípios constitutivos e findos das universidades, elementos que quando não executados adequadamente, contrariam e violam o preceito legal.

Em meio aos desafios impostos pelo princípio da indissociabilidade e o cumprimento do que preconiza o SINAES (2004) em relação à RSU, este artigo tem como objetivo avaliar como a prática da extensão universitária contribui para sua consolidação. Para dar conta deste ideário, utilizou-se como método a pesquisa descritiva (GODOY, 1995; CERVO, BERVIAN, 2003). Quanto à forma, caracteriza-se como uma pesquisa documental (APPOLINÁRIO, 2009; PÁDUA, 2011), que contempla o seguinte corpus investigativo: missão, visão e valores da Universidade do Oeste de Santa Catarina (UNOESC); Plano de Desenvolvimento Institucional (PDI); Sistema Nacional de Avaliação da Educação Superior (SINAES); e o projeto de extensão Universidade da Melhor Idade de Chapecó (UMIC) - relatórios de campo.

Considerando a tipologia da UNOESC, uma instituição comunitária, a dimensão da RSU, SINAES (2004), assume importância ímpar, sendo que, além do que indicam os dispositivos legais, a própria caracterização da IES a coloca numa posição de serviço à comunidade local e regional. Os resultados esperados com este estudo demonstram-se extremamente relevantes para a UNOESC, visto ser o lócus de atuação e para as IES, em especial aquelas com características comunitárias. Nesse norte, ganha o meio Universitário, pois terá disponível uma análise criteriosa sobre o real papel das ações de extensão no que tange à RSU, ampliando a visão acadêmica sobre suas práticas de indissociabilidade, aferindo sua contribuição com o Desenvolvimento Social.

Este trabalho está organizado em seis seções: a Introdução, que apresenta a caracterização do estudo, a problemática, os objetivos propostos e resultados esperados; na segunda seção apresenta-se a fundamentação teórica que contempla a indissociabilidade entre ensino, pesquisa e extensão, além da responsabilidade social universitária; no apartado três apresentam-se os procedimentos metodológicos empregadas no estudo; o quarto tópico destina-se ao relato da experiência da UMIC e respectiva análise documental; na quinta seção estão delineadas as considerações finais com as respectivas correlações teóricas; por fim, o último tópico apresenta o referencial teórico utilizado para o estudo. 


\section{Fundamentação teórica}

A seguir, apresenta-se o suporte teórico deste texto, que permitirá a melhor compreensão da indissociabilidade entre o ensino, pesquisa e extensão, com ênfase na extensão universitária, como elemento integrador para a efetivação da RSU; definições e percepções sobre a RSU, por se tratar de um elemento central para a compreensão dos resultados esperados pelas universidades quando empreendidas ações de extensão universitária.

a) Indissociabilidade entre ensino, pesquisa e extensão: resultou de processos sociais, ao longo das décadas, que a incluíram como um requisito para as instituições serem consideradas universidades (MOITA e ANDRADE, 2013). Este princípio, a indissociabilidade entre ensino, pesquisa e extensão é apontado como referência do padrão de qualidade acadêmica para as instituições de ensino superior do país (ANDES, 1982). Trata-se de um movimento iniciado a partir de uma emenda apresentada pelo Fórum Nacional de Educação na Constituinte à Assembleia Nacional Constituinte, que propunha a indissociabilidade entre ensino, pesquisa e extensão como um novo paradigma para a universidade brasileira, sendo incorporada à Constituição brasileira de 1988 em seu artigo 207, que estabelece: "As universidades gozam de autonomia didático- científica, administrativa e de gestão e obedecerão ao princípio da indissociabilidade entre ensino, pesquisa e extensão".

Nesse sentido, Pucci 1991, destaca que o conceito de indissociabilidade entre ensino, pesquisa e extensão se apresenta como referência para a organização do trabalho pedagógico, embora de difícil concretização em face das condições políticas e estruturais da educação superior, tornando-se premissa para pensar e propor alternativas para esse nível de ensino, incorporando-se como elemento de expressão dos movimentos acadêmicos, científicos e culturais. Trata-se de um movimento consagrado na Constituição de 1988, fato que eleva a expressão indissociabilidade entre ensino, pesquisa e extensão como caminho elementar para a construção de uma Universidade de bom nível acadêmico, com autonomia científica, democrática, independente, que se coloca a serviço da sociedade voltada para a formação cidadã da população brasileira (PUCCI, 1991).

Conforme a legislação, o tripé formado pelo ensino pesquisa e extensão constitui o eixo fundamental das universidades brasileiras e não pode ser compartimentado. Dessa forma, enquanto funções básicas da universidade, devem ser equivalentes e merecer igualdade de tratamento por parte das instituições de ensino superior, pois, ao contrário, estarão violando esse preceito constitucional. A indissociabilidade é um princípio orientador da qualidade da produção universitária, pois afirma como necessária a tridimensionalidade do fazer universitário autônomo, competente e ético (MOITA; ANDRADE, 2013). 
Complementarmente, Pucci (1991) e Raye (2003) destacam que a indissociabilidade implica na interação das três atividades da universidade - o ensino, a pesquisa e a extensão -. Embora cada um tenha uma essência distinta de práticas pedagógicas, sempre haverá momentos de intersecção, o que oxigena a produção do conhecimento ao permitir sua renovação com alunos, professores e a sociedade. Ainda, proporciona vivências que estimulam novos questionamentos sobre a realidade e novos conhecimentos, promovendo a democratização da universidade. Entende-se que essas práticas ocorrem em um estado democrático de direito, abrangendo os princípios democráticos e humanistas.

A assimilação do conceito de indissociabilidade, em relação aos termos ensino, pesquisa e extensão é imprescindível para o planejamento, desenvolvimento e avaliação das atividades curriculares que pretendem tomar o conceito como princípio norteador das práticas cotidianas do ensino superior. Assim, a indissociabilidade caracteriza-se como um processo multifacetado de relações e de correlações que busca a unidade da teoria e da prática (RAYS, 2003).

Nessa ótica, Moita e Andrade (2013) adicionam que a indissociabilidade entre ensino, pesquisa e extensão deve ocorrer e seu resultado requer um dinamismo nos vários espaços da universidade capaz de facilitar a troca de conhecimentos entre esses espaços e aprimorá-los para torná-los momentos verdadeiramente impulsionadores de reflexões sobre a realidade e proposições de soluções para os conflitos que a permeiam.

b) Extensão Universitária: a Extensão Universitária é uma das funções que compõem os pilares da instituição universidade, entretanto, tem sido alvo de críticas, proposições e cortejada por diversos setores da sociedade, assumindo ao longo dos anos diferentes concepções teóricas e ideológicas, que influenciam na própria concepção de Universidade. As Análises dos discursos dos estudiosos do tema apresentam abordagens teóricas que fundamentam a extensão como função social da Universidade, ainda, no contexto da globalização, abertura de mercado e privatização das instituições públicas, assim, uma nova abordagem teórica e prática tem se imposto à extensão universitária: a mercadológica (JEZINE, 2004).

Segundo a autora, é relevante analisar as abordagens de extensão como função acadêmica da universidade, na perspectiva de uma ação incorporada ao quefazer universitário, estando no mesmo patamar de atividade curricular como o ensino e a pesquisa. Assim, a extensão universitária é parte orgânica do currículo na formação de educadores e profissionais, pois a partir de sua dinâmica social se dá a produção das relações interdisciplinares entre as práticas de ensino e pesquisa, caracterizando-se como o elo de integração do pensar e do fazer, da relação teoria-prática na produção do conhecimento (JEZINE, 2004).

Por outro norte, Rays (2003) apresenta a extensão universitária sob a acepção crítica, visto ser um processo que vai até a sociedade, aos diversos segmentos sociais, a fim de

\begin{tabular}{l|l|l|l|l|l|l}
\hline (C) Rev. Inter. Educ. Sup. & Campinas, SP & v.2 & n.1 & p.191-213 & jan./abr. 2016 & ISSN 2446-9424
\end{tabular}


estender os produtos do ensino e pesquisa gerados no âmbito acadêmico. Nesse sentindo, a extensão universitária caracteriza-se como um processo que traz para a universidade tanto os problemas, quanto os conhecimentos gerados nos mais variados segmentos da sociedade, argumentos compartilhados por Jezine (2004); Rays (2003); Moita e Andrade (2013).

Segundo Rays (2003) e Serrano (2013), ainda persiste a concepção assistencialista em alguns projetos de extensão, mas também se observa no panorama das atividades extensionistas das universidades uma alteração de concepção, que se expressa em uma nova postura para a extensão universitária, pautada no princípio educativo, como a relação teóricoprática, proporcionando um novo pensar e fazer, capaz de desenvolver uma concepção histórica de sujeito e de sociedade. Essa visão é amplamente desenvolvida por Moita e Andrade (2013), afirmando que a extensão universitária deve superar a dimensão de prestação de serviços assistencialistas, redimensionando-se com ênfase na relação teoriaprática, na perspectiva de uma relação dialógica entre universidade e sociedade, como oportunidade de troca de saberes.

A extensão universitária vivencia um momento extremamente importante para sua consolidação no meio acadêmico. Segundo Serrano (2013); Rays (2003); Moita e Andrade (2013), para que isso aconteça, as práticas institucionais por meio do próprio fazer extensionista e das normatizações universitárias necessitam melhor dispor-se diante das funções acadêmica, social e articuladora da universidade, não sendo considerado um desafio pequeno, visto que o plano nacional de extensão está distante de ser uma realidade plena nas universidades brasileiras.

Num olhar mais abrangente, a extensão universitária é um processo educativo, cultural e científico que visa o fortalecimento da relação universidade e sociedade, priorizando a superação das condições de desigualdade e exclusão existentes, por meio de projetos sociais, socializando seu conhecimento e disponibilizando serviços, exercendo sua responsabilidade social, e cumprindo sua missão de melhorar a vida dos cidadãos. (SERRANO, 2013; JEZINE, 2004; RAYS, 2003). Dessa forma, a extensão universitária desempenha a função de socialização do conhecimento junto à comunidade externa, num processo de ação comunitária visando sua autonomia.

c) Responsabilidade Social Universitária (RSU): A estrutura avaliativa do Sistema contempla três componentes: das IES (a autoavaliação, a avaliação externa), a avaliação dos cursos de graduação (Organização Didático-Pedagógica, o Perfil do Corpo Docente e as Instalações físicas) e a dos estudantes (Exame Nacional de Desempenho de Estudantes - ENADE). Também complementam o SINAES os seguintes instrumentos de informação: o Censo da Educação Superior e o Cadastro de Cursos e Instituições (INEP, 2014). O conjunto de dimensões avaliativas do SINAES estão organizados em cinco eixos e suas respectivas dimensões de avaliação, conforme indicado no quadro 1: 
QUADRO 1 - Eixos e dimensões avaliativas do SINAES

\begin{tabular}{|l|l|}
\hline \multicolumn{1}{|c|}{ Eixo } & \multicolumn{1}{c|}{ Dimensões } \\
\hline $\begin{array}{l}\text { Eixo 1: Planejamento e Avaliação } \\
\text { Institucional }\end{array}$ & Dimensão 8: Planejamento e Avaliação \\
\hline $\begin{array}{l}\text { Eixo 2: Desenvolvimento } \\
\text { Institucional }\end{array}$ & $\begin{array}{l}\text { Dimensão 1: Missão e Plano de Desenvolvimento Institucional. } \\
\text { Dimensão 3: Responsabilidade Social da Instituição. }\end{array}$ \\
\hline Eixo 3: Políticas Acadêmicas & $\begin{array}{l}\text { Dimensão 2: Políticas para o Ensino, a Pesquisa e a Extensão } \\
\text { Dimensão 4: Comunicação com a Sociedade } \\
\text { Dimensão 9: Política de Atendimento aos Discentes }\end{array}$ \\
\hline Eixo 4: Políticas de Gestão & $\begin{array}{l}\text { Dimensão 5: Políticas de Pessoal } \\
\text { Dimensão 6: Organização e Gestão da Instituição } \\
\text { Dimensão 10: Sustentabilidade Financeira }\end{array}$ \\
\hline Eixo 5: Infraestrutura Física & Dimensão 7: Infraestrutura Física \\
\hline
\end{tabular}

Fonte: Elaborado a partir da Nota Técnica N 14/2014-CGACGIES/DAES/INEP/MEC

No eixo 2, Desenvolvimento Institucional, foco do estudo proposto, são avaliadas as Dimensões 1 e 3: Missão e Plano de Desenvolvimento Institucional e a Responsabilidade Social da Instituição, respectivamente, contemplando os seguintes aspectos: Missão institucional, metas e objetivos do PDI; coerência entre o PDI e as atividades de ensino de graduação e de pós-graduação; coerência entre o PDI e as práticas de extensão; coerência entre o PDI e as atividades de pesquisa/iniciação científica, tecnológica, artística e cultural; coerência entre o PDI e as ações institucionais no que se refere à diversidade, ao meio ambiente, à memória cultural, à produção artística e ao patrimônio cultural; coerência entre o PDI e as ações institucionais voltadas para o desenvolvimento econômico e social; coerência entre o PDI e ações de responsabilidade social: inclusão social; coerência entre o PDI e ações afirmativas de defesa e promoção dos direitos humanos e igualdade étnico-racial; internacionalização: coerência entre o PDI e as ações institucionais.

O SINAES teve como propósito, desde a sua promulgação em 2004, abrir as portas de oportunidades para a responsabilidade social na gestão universitária. Dessa forma, a Responsabilidade Social se constitui numa exigência para qualquer IES, seja ela pública ou privada (ASHLEY, FERREIRA, REIS, 2006). Dessa forma, para Vallayes (2006, p. 39):

A Responsabilidade Social Universitária exige, a partir de uma visão holística, a articulação dos diversos setores da instituição, em um projeto de promoção social de princípios éticos e de desenvolvimento social equitativo e sustentável, com vistas à produção e transmissão de saberes responsável e à formação de profissionais cidadãos igualmente responsáveis.

Complementarmente, Calderón (2006, p.8), destaca que:

Se por um lado, o entendimento da Responsabilidade Social Universitária que se tinha há mais de quatro décadas ainda mantém vigência, podemos afirmar que ele tem adquirido novos matizes em decorrência das rápidas mudanças ocorridas no mundo, em termos políticos, econômicos, culturais, informacionais decorrentes da crise do Estado de Bem-Estar, da hegemonia do neoliberalismo, da aceleração do processo de globalização econômica, do surgimento da sociedade global de informação e do conhecimento e, principalmente, do fim da guerra fria.

Nessa linha, Carrizzo (2006) argumenta que as Universidades devem se transformar em um instrumento acelerador do processo de transformação social, atribuindo à \begin{tabular}{l|l|l|l|l|l|l} 
(C) Rev. Inter. Educ. Sup. & Campinas, SP & v.2 & n.1 & p.191-213 & jan./abr. 2016 & ISSN 2446-9424
\end{tabular} 
Universidade a missão de ditar o ritmo da história, visão compartilhada também por Florestan Fernandes (1975). A RSU deve considerar as auguras de um mundo complexo, de diferenças sociais e desigualdades de oportunidades. Por estas argumentações, ganha destaque a visão de Responsabilidade Social associada diretamente ao desenvolvimento humano, condição compartilhada por Wagenberg (2006), Kliksberg (2006), Vallaeys (2006), e Carrizo (2006), Morin (2002). Especificamente, Morin (2002) acrescenta que o desenvolvimento sob o viés unicamente econômico provoca a prevalência da pobreza material e da alma dos socialmente excluídos, destacando a necessidade do diálogo permanente entre os processos técnicos e econômicos, aliados a preceitos éticos de solidariedade e responsabilidade.

Sob esta vertente, Santos (1995) enfatiza que os pressupostos da responsabilidade social devem atender critérios além da vertente econômica, estimulando a ótica da orientação social e política, diante de problemas sociais. O autor destaca que o desafio está no alinhamento entre a sustentabilidade institucional, sob o ponto de vista econômico, e os indicativos de que a RSU valoriza o bem-estar social e a vida humana como finalidade absoluta.

Nessa ótica, Vallaeys (2006) defende uma nova dinâmica universitária, permeando três fatores - a garantia da responsabilidade social da ciência, a promoção da formação cidadã democrática e a formação calcada nos fundamentos da formação transversal de agentes para o desenvolvimento. Este viés formativo deve ser disseminado por meio do ensino, da pesquisa e da extensão, elementos tradicionais e basilares das Universidades que, segundo Vallaeys (2006, p. 45), permitem a "construção das pontes entre a universidade e a sociedade, a concretização do compromisso social da universidade e a reflexão ética sobre a dimensão social do ensino e da pesquisa e têm sido uma atribuição da chamada extensão universitária".

Considerando essa perspectiva, Calderón (2006) e Vallaeys (2006) compartilham que a RSU carece de uma visão mais abrangente e sistêmica, considerando as diversas partes da instituição em um projeto de promoção social com princípios éticos, sustentáveis, justos e de desenvolvimento social, sustentando o processo de ensino e aprendizagem para a transmissão de saberes com vistas à formação de cidadãos também responsáveis socialmente. Nessa perspectiva, Jimenez et al. (2006, p. 15) destaca que a RSU é a:

[...] capacidade que possui a universidade de difundir e colocar em prática um conjunto de princípios e valores, gerais e específicos, por meio de quatro processos considerados chaves: gestão, docência, pesquisa e extensão universitária, respondendo socialmente desta forma perante a própria comunidade universitária e o país onde está inserida.

A visão de Jimenez (2006) coaduna-se com as perspectivas anteriores, Calderón (2000, 2003, 2004, 2005, 2006); Wagenberg (2006), Kliksberg (2006), Vallaeys (2006); Carrizo (2006) e acrescenta um componente fundamental para a execução da Responsabilidade Social, que o autor chama de elemento chave: a gestão, contribuição que deve se consolidar a partir da definição de mecanismos administrativos que viabilizem a Responsabilidade Social nas Universidades. Verifica-se, portanto, que passa necessariamente

\begin{tabular}{l|l|l|l|l|l|l} 
(C) Rev. Inter. Educ. Sup. & Campinas, SP & v.2 & n.1 & p.191-213 & jan./abr. 2016 & ISSN 2446-9424
\end{tabular}


pela postura e modelo de Governança das Universidades, o desejo executivo de direcionar as atividades institucionais - Ensino, Pesquisa e Extensão aliados à postura de gestão, para atender ao pressuposto transversal da Responsabilidade Social nas ações e processos de interação com a sociedade.

A RSU, sob o ínterim da gestão, ganha contornos que, segundo Herrera (2009), incluem uma gama de ações e processos, cujo objetivo é responder às demandas de seu ambiente de maneira adequada, formando um elo entre o conhecimento gerado dentro da Universidade e as necessidades locais, perfazendo uma nova postura de gestão sob este prisma. Nessa ótica, Macedo (2004) apregoa que a gestão assume uma nova dinâmica, que vai além da tradicional administração de patrimônio e de atividades acadêmicas, suscitando um perfil democrático que fortalece a gestão social e politicamente democrática. Dentro dessa visão, Calderón (2006) esclarece que existe uma estreita relação entre as práticas acadêmicas - Ensino, Pesquisa e Extensão -, e as práticas gerenciais - conjunto de processos e estruturas gerenciais que permitam às Universidades cumprir sua missão institucional -, as quais deveriam estimular os princípios e valores verificados na base da Responsabilidade Social Universitária. Elementos que, para Pernalete e Ortega (2010), indicam como a possibilidade de criação de uma simbiose entre universidade/sociedade, permitiria um elo que valorizasse todos os atores envolvidos nesse processo, da Universidade à Sociedade.

Considerando este cenário, a compreensão da RSU sob o olhar teórico permite refinar a reflexão sobre a Universidade no que tange: à sua estrutura funcional, ao direcionamento das atividades acadêmicas e à sua forma de Governança. Cabe ressaltar que a preocupação com a Responsabilidade Social é um elemento presente em outras tipologias organizacionais, tais como as empresas. De acordo com Drucker (2009, p. 84):

Cada um é responsável pelo impacto que causa. [...] Cedo ou tarde a sociedade vai considerar qualquer impacto causado um ataque à sua própria integridade e vai cobrar um alto preço daqueles que não tomaram para si a responsabilidade de trabalhar para eliminar o impacto ou para descobrir uma solução para o problema.

O autor chama a atenção para o fato de que as organizações precisam estar atentas e se "juntar às preocupações fundamentais da comunidade com os aspectos qualitativos da vida, isto é, bens e serviços econômicos, preocupação com a qualidade de vida, ou seja, com o ambiente físico, humano e social do homem moderno e da comunidade moderna". Continua explicando que:

Há apenas alguns anos, tanto os administradores quanto os economistas consideravam a dimensão social tão intangível que não seria possível estabelecer objetivos de desempenho para ela. Sabemos agora que o intangível pode transformar-se em muito tangível mesmo. Lições como a do consumismo ou a do ataque as indústria que prejudicam o meio ambiente são métodos dispendiosos para aprender que uma empresa precisa pensar em suas responsabilidades e nos impactos que causa e estabelecer objetivos para ambos (Drucker, 2009, p. 49).

Vallaeys (2006, p.36) assinala que a: 
[...] Responsabilidade Social Empresarial é um conjunto de práticas da organização que integra sua estratégia corporativa e que tem como finalidade evitar danos e/ou gerar benefícios para todas as partes envolvidas na atividade da empresa (clientes, empregados, acionistas, comunidade, periferia etc.), com finalidades racionais, que devem redundar em benefício tanto da organização como da sociedade.

Concernente aos benefícios da Responsabilidade Social Empresarial (SER) destaca-se que a:

RSE é o compromisso empresarial de contribuir para o desenvolvimento econômico sustentável, trabalhando em conjunto com os empregados, suas famílias, a comunidade local e a sociedade em geral para melhorar sua qualidade de vida, de maneira que sejam boas tanto para as empresas como para o desenvolvimento (BANCO MUNDIAL, 2002).

Já Friedman (1970) caracteriza, de forma pragmática, a RSE como um conceito que as empresas, por meio de suas práticas, colaboram voluntariamente para a melhoria da sociedade, valorizando o desenvolvimento econômico, e a preservação do meio ambiente para a melhoria da qualidade de vida da sociedade. Nesse sentido, Paoli (2002) destaca que a RSE deve abranger o cumprimento das normas trabalhistas, o desenvolvimento econômico com transparência das contas, respeito ao meio ambiente e investimentos reais em melhoria da qualidade de vida da sociedade que interage com a organização.

Neste contexto, a RSU carece de estratégias claras para sua execução, conforme aborda Vallaeys (2006), sugerindo quatro linhas de ações institucionais para sua efetivação: 1) Gestão interna: transformar a Universidade numa comunidade ética, socialmente exemplar, democrática e transparente economicamente e politicamente, com viés no desenvolvimento sustentável; 2) Docência: direcionar a aprendizagem baseada em projetos sociais, como enfoque multi e interdisciplinar, dado seu direcionamento na aprendizagem articulada com a pesquisa, ensino e extensão; 3) Pesquisa: fomento a projetos com fins de desenvolvimento social, utilizando estratégias integradas com a comunidade com viés na resolução de problemas locais; 4) Projetos sociais: proceder uma interface entre cursos, departamentos e pesquisadores e estudantes, engajados em projetos que se tornem fonte de pesquisa aplicada e de recursos didáticos para a comunidade universitária.

\section{Metodologia}

Com base na tipologia apresentada por Cervo e Bervian (2003), o estudo se caracteriza por ser uma pesquisa descritiva, pois "observa, registra, analisa e correlaciona fatos ou fenômenos (variáveis) sem manipulá-los" (CERVO, BERVIAN, 2003, p. 66). Quanto ao procedimento, constitui-se em uma pesquisa documental por meio da qual "são investigados documentos a fim de se poder descrever e comparar usos e costumes, tendências, diferenças e outras características. Estuda a realidade presente, e não o passado, como ocorre com a pesquisa histórica” (Idem, p. 67). Godoy (1995, p. 21-22), referindo-se aos documentos, salienta que tal expressão ao ser compreendida de forma ampla, inclui: 
[...] os materiais escritos (como, por exemplo, jornais, revistas, diários, obras literárias, científicas e técnicas, cartas, memorandos, relatórios), as estatísticas (que produzem um registro ordenado e regular de vários aspectos da vida de determinada sociedade) e os elementos iconográficos (como, por exemplo, sinais, grafismos, imagens, fotografias, filmes). Tais documentos são considerados primários "quando produzidos por pessoas que vivenciaram diretamente o evento que está sendo estudado", ou secundários, "quando coletados por pessoas que não estavam presentes por ocasião da sua ocorrência (grifo da autora).

Pádua (2011, p. 69) explica que documento [...] é toda base de conhecimento fixado materialmente e suscetível de ser utilizado para consulta, estudo ou prova (grifo do autor). Appolinário (2009, p. 67) define documento como sendo "Qualquer suporte que contenha informação registrada, formando uma unidade, que possa servir para consulta, estudo ou prova. Incluem-se nesse universo os impressos, os manuscritos, os registros audiovisuais e sonoros, as imagens, entre outros".

O corpus investigativo compõe-se pelos documentos apresentados no quadro 2.

QUADRO 2 - Constituição do corpus investigativo

\begin{tabular}{|l|}
\hline \multicolumn{1}{|c|}{ Documentos } \\
\hline$\bullet$ Missão, Visão e Valores Institucionais da UNOESC \\
\hline • Plano de Desenvolvimento Institucional (PDI). \\
\hline - Sistema Nacional de Avaliação da Educação Superior (SINAES). \\
\hline - Projeto Pedagógico dos Cursos de Extensão da Universidade da Melhor Idade - UMIC \\
\hline • Relatórios de campo conclusivos de cada etapa do projeto UMIC \\
\hline Fonte: Elaborado a partir dos dados em FUNOESC (2015).
\end{tabular}

Considerando os preceitos institucionais da UNOESC e o seu PDI, somados ao projeto de Extensão UMIC, em correlação com os fundamentos teóricos que sustentam este trabalho, será refinado o olhar da contribuição efetiva da Extensão para a consolidação da RSU.

\section{Apresentação e discussão dos resultados}

A seguir serão delineados os preceitos institucionais da UNOESC, explicitando a caracterização e desdobramentos da UMIC e, por fim, apresenta-se a análise crítica da contribuição do projeto de extensão UMIC para a consolidação da RSU.

A Universidade do Oeste de Santa Catarina (UNOESC): vínculo entre os princípios constitutivos (missão, visão e valores) o Plano de Desenvolvimento Institucional (PDI) e o compromisso com a Responsabilidade Social Universitária

A UNOESC, instituição reconhecidamente de utilidade pública, trabalha em prol da coletividade, entidade filantrópica, que permite conceder benefícios, como bolsas de estudos e modalidades de assistência social. Considerada uma instituição de referência no estado de

\begin{tabular}{l|l|l|l|l|l|l} 
(C) Rev. Inter. Educ. Sup. & Campinas, SP & v.2 & n.1 & p.191-213 & jan./abr. 2016 & ISSN 2446-9424 \\
\hline
\end{tabular}


Santa Catarina, conta atualmente com cinco Campi: Joaçaba, Videira, Xanxerê, São Miguel do Oeste e Chapecó, com a missão de "formar pessoas, produzir conhecimento e oferecer extensão e serviços, promovendo o desenvolvimento institucional e regional" (UNOESC, 2013).

A missão expressa a finalidade maior a que uma instituição universitária é chamada a responder. Dessa forma, ela transcende a realidade contingente e transitória, possui caráter de utopia, no sentido de que é possível pensar e projetar a Instituição no presente e no futuro. A missão para a qual a Unoesc foi constituída tem a ver com a sua história, com a sua identidade e com os seus fins.

Considerada uma das maiores instituições propulsoras do desenvolvimento, da pesquisa, e das perspectivas socioculturais e educacionais nas regiões de abrangência, a Unoesc tem previsto em seu PDI (Unoesc, p.25) a visão de "ser uma universidade reconhecida pela excelência acadêmica e atuação como agente de desenvolvimento regional." O desenvolvimento da Instituição vai além das construções que edificou ao longo desses anos, ele se manifesta, igualmente, na transformação da cultura, do conhecimento, das condições de formação das pessoas que tiveram acesso ao ensino superior e das condições de melhoria da qualidade de vida pessoal e profissional das pessoas. A visão expressa as expectativas, os desejos da comunidade acadêmica e da sociedade em relação a um futuro desejável e possível para a instituição. Para isso, ela necessita ser abrangente, desafiadora, inspiradora e inovadora.

Valores são princípios de conduta construídos e seguidos pelos colaboradores da instituição, dando identidade e credibilidade à instituição, devem ser significativos, compartilhados e duradouros, portanto, a Unoesc nasceu e cresceu alicerçada em seus valores baseados na ética, no humanismo, na cooperação, no comprometimento, na responsabilidade social, na inovação e na solidez (UNOESC, 2013). A identidade comunitária da Unoesc se reflete nas ações que desenvolve nas áreas da educação, saúde, assistência social, tecnológica, ambiental, cultural e de lazer, com objetivo de difundir o conhecimento e levar qualidade de vida às pessoas, preservando seus valores.

As ações da Unoesc sempre foram alicerçadas na possibilidade de oferecer o melhor à população da mesorregião Oeste catarinense, criando condições e perspectivas para o desenvolvimento das regiões. Em seu PDI - Plano de Desenvolvimento Institucional (20132017), no item 2.8, aborda especificamente sobre a responsabilidade social da instituição, onde a função social da Unoesc extrapola a sua missão de formar pessoas, produzir e difundir o conhecimento. Por ser uma Instituição comunitária, a Unoesc permeia a vida da comunidade regional, compõe o tecido social presente no cotidiano de famílias, empresas e organizações (UNOESC, 2013).

Nesse sentido, a Unoesc (2013) destaca que os programas desenvolvidos pela instituição são voltados à política de integração da Instituição com a comunidade. Os projetos 
políticos pedagógicos dos cursos, os estágios, os Trabalhos de Conclusão de Curso (TCCs), as monografias dos cursos de graduação e pós- graduação e as dissertações de mestrado, teses de doutorado, se voltam para as problemáticas regionais, promovendo uma integração significativa entre a comunidade e a Unoesc, além de articular o ensino, a pesquisa e a extensão.

\section{Caracterização do projeto de extensão: Universidade da Melhor Idade (UMIC)}

Atualmente, inúmeros são os estudos que têm demonstrando o aumento quantitativo da expectativa de vida da população mundial, bem como é atual a pretensão de relacionar os aspectos da qualidade de vida dos idosos aliados a este salto quantitativo. A expectativa no Brasil quanto ao número de pessoas idosas poderá se igualar aos países europeus até o ano 2025, devido à melhoria na qualidade de vida e ao aumento na expectativa de vida (AZINI FILHO et. al. 2010). Tem-se a expectativa de que, também em 2025, estaremos com um contingente de idosos da ordem de, aproximadamente, 32 milhões de pessoas.

$\mathrm{O}$ autor destaca ainda que os idosos experimentam o envelhecimento de forma heterogênea, isto compreendido a partir de questões de gênero, religião, cultura, nível de instrução e renda a que estão vinculados. Além disso, a sociedade atual valoriza de modo extremo as esferas de produção e consumo, nas quais o patrimônio familiar é substituído pelos projetos individuais. Sendo assim, os idosos muitas vezes são identificados como inativos ou improdutivos, sendo frequentemente distanciados do acesso aos bens e serviços de nossa comunidade. Tal realidade tem imposto a necessidade de desenvolverem-se políticas públicas que atendam às demandas deste segmento. Essas políticas voltam-se à saúde, à educação, à assistência social, à integração e à reintegração social, bem como a oportunizar condições de vida digna a esta população.

Surgiram nos últimos anos vários programs brasileiros voltados à população idosa, o que tem dado visibilidade a esta parcela da população, passando uma imagem desse tempo de vida como de realizações e de atividades. Aliada a tal tendencia é que, em 2011, surge a Universidade da Melhor Idade de Chapecó - UMIC, projeto desenvolvido pela Prefeitura Municipal de Chapecó, por meio da Secretaria de Assistência Social, em parceria com a Universidade do Oeste de Santa Catarina - Unoesc. Os espaços internos da universidade, tradicionalmente ocupados por jovens universitários, passam a oportunizar o acesso à construção de conhecimento e continuidade da aprendizagem aos alunos idosos.

Implantado em 2011, o projeto UMIC contou com o ingresso de 122 idosos e formaram-se em junho de 2012, apenas 97, em sua segunda edição ingressaram 81 idosos, e formaram-se 56. As desistências detectadas na primeira e segunda edição da UMIC foram por motivos relacionados à saúde dos idosos ou de seus familiares e, dessa forma, alguns necessitaram desvincular-se, sendo registrados dois falecimentos, além de mudança de cidade e falta de apoio familiar na continuidade dos estudos. 
$\mathrm{Na}$ terceira edição ingressaram 49 idosos e formaram-se apenas 29, regida por algumas particularidades, entre elas, o fato de ser uma turma mista - alguns alunos possuíam o grau de instrução elevado -, gerando intolerância do grupo, acendendo diversas discussões e consequentemente muitas desistências. Por outro lado, a turma apresentou um grau avançado de maturidade, evolução, liderança e realizações dos objetivos propostos, considerada uma turma ativa. No quesito das aulas, superou as expectativas devido à aceitação relacionada aos professores e atividades propostas, tanto que surgiram atividades extras e em certos momentos compareciam à Instituição quatro vezes na semana, com um número excelente de participantes.

Atualmente, na quarta edição da UMIC, ingressaram 33 idosos, sendo que 28 estão frequentando as aulas regulamente, com previsão para a conclusão desta edição ao final de 2016.

Considerada uma execelente parceria entre o poder público e o privado que vem ocorrendo de forma assertiva há diversos anos, com o intuito de fortalecer a responsabilidade social por meio da atividade de extensão, tem como seu principal objetivo a formação integral do idoso. Neste processo se estabelece a educação como possibilidade de construir conhecimentos, proporcionando lazer, qualidade de vida, saúde e bem-estar ao grupo atendido pelo projeto. Este processo se traduz em realidade a partir do exercício das atividades teóricas e práticas vivenciadas no projeto pelos idosos, permitindo em certa medida a integração e reintegração social desses alunos cidadãos, muitos à margem de oportunidades desta natureza.

Embora os idosos tenham adquirido vasto conhecimento no decorrer da vida, nunca é tarde para aprender e repassar os ensinamentos, por essa razão cresce o número de universidades que abrem as portas para a terceira idade. Nesse caminho, a formação oferecida na UMIC persegue formação teórica e prática, enriquecida com atividades extracurriculares.

Neste processo, se estabelece a educação como possibilidade de construir conhecimentos, proporcionando lazer, qualidade de vida, saúde e bem-estar aos idosos com mais de 60 anos, suprindo algumas necessidades da demanda desta faixa etária. A longevidade da população idosa é realidade, tende a aumentar e um dos fatores que tem colaborado com esta expectativa são os projetos sociais com características da UMIC que possibilitam a integração e reintegração social.

A UMIC se consolidou como um curso de extensão, sem exigência de escolaridade e com as atividades desdobradas em componentes curriculares teóricos e práticos, distribuídas em três semestres, com encontros divididos em duas vezes por semana, das 14 horas às 16 horas 15 minutos, sendo que os acadêmicos recebem sua certificação ao completar as 240 horas do curso. $\mathrm{O}$ projeto aborda componentes curriculares com objetivos que atendem às necessidades cotidianas da faixa etária, distribuídos conforme tabela a seguir: 
TABELA 1 - Disciplinas ofertadas

DISCIPLINA

Relacionamento

Familiar entre

Gerações

Saúde e Qualidade de Vida

Direitos e Deveres do Cidadão

História do Oeste
de Santa Catarina

Religiões do

Mundo OBJETIVOS

Propõe-se a oferecer ao aluno um maior entendimento de como as mudanças no ciclo de vida familiar afetam os relacionamentos, proporcionando uma reflexão acerca das relações familiares entre as gerações.

Identifica a necessidade de educar e prevenir a população para a prevenção e cuidados com relação à distinção entre o normal (esperado pelo envelhecimento) e o patológico relacionado às doenças mais prevalentes nesta faixa etária, com intuito de aumentar a expectativa e qualidade de vida da população.

Esclarece as positivações do Direito em Lei por proteger e legitimar pela estrutura estatal, sendo o Estatuto do Idoso um avanço que regulamenta princípios já garantidos pela Constituição de 1988

Revela a importância do conhecer como ocorreu a ocupação do espaço da região oeste de Santa Catarina, oportunizando discussões acerca e propiciando posicionamento crítico frente aos acontecimentos do passado.

\begin{tabular}{l|l} 
& foções Básicas de \\
Política & T \\
\hline Artes I e II & M
\end{tabular}

Premissa que resgata e desperta no idoso o sentido da vida, através dos valores essenciais que já possui, sendo o amor, respeito, fraternidade, compaixão e tolerância, trabalhando o fenômeno religioso na sua transcendência e manifestação espiritual, fortificando-os no autoconhecimento.

Tem sua relevância ao oferecer ao aluno a compreensão da estrutura subjacente à organização social.

Motiva os idosos ao conhecimento básico, para aprofundarem-se na pesquisa de materiais e técnicas, entender a arte em todas as partes, a compreender como forma de expressão e comunicação e sua importância na evolução das civilizações, desenvolvendo o senso crítico dos alunos.

\begin{tabular}{l|l}
\hline Turismo I, II e III & Em consideração que a melhor idade é um dos maiores nichos de mercado para o
\end{tabular} turismo, visando potencializá-los como turistas consumidores conscientes, estimular para todos os fatores que fazem do mercado turístico o que mais cresce no mundo, por isso a apresentação dos impactos do turismo e a discriminação de todos os atores que se envolvem na atividade turística é fundamental.

Informática I, II e
III

Passou a ser uma grande aliada no dia a dia das pessoas tornando-se indispensável, por estarmos vivenciando a era da informação, de novas tendências e tecnologias auxiliando o idoso na socialização.

\begin{tabular}{|c|c|}
\hline $\begin{array}{l}\text { Planejamento } \\
\text { Financeiro Pessoal }\end{array}$ & $\begin{array}{l}\text { Indispensável à vida das pessoas e das empresas por possibilitar com antecedência os } \\
\text { caminhos trilhados, visando maximizar os resultados econômico-financeiros, trazendo } \\
\text { tranquilidade e organização. }\end{array}$ \\
\hline $\begin{array}{l}\text { Atividade Física I, } \\
\text { II e III }\end{array}$ & $\begin{array}{l}\text { Define que o envelhecimento é inevitável, mas que alguns fatores podem retardar o seu } \\
\text { aparecimento. Entre estes fatores, a prática da atividade física regular auxilia no retardo } \\
\text { do envelhecimento, e também colabora para que os idosos tenham uma qualidade de } \\
\text { vida melhor. }\end{array}$ \\
\hline Seminário I, II e III & $\begin{array}{l}\text { Busca atender às necessidades dos idosos por meio da informação, visando à prevenção } \\
\text { geralmente na área da saúde, trazendo informações pertinentes ao dia a dia }\end{array}$ \\
\hline $\begin{array}{l}\text { Alimentação } \\
\text { Saudável }\end{array}$ & $\begin{array}{l}\text { Proporciona conhecimentos mais amplos relacionados à alimentação saudável e seus } \\
\text { benefícios aos idosos devido a necessidades específicas da faixa etária }\end{array}$ \\
\hline $\begin{array}{l}\text { Geografia de Santa } \\
\text { Catarina }\end{array}$ & $\begin{array}{l}\text { Continuidade de conhecimentos do cotidiano, município e local onde mora na } \\
\text { compreensão das relações de sociedade e espaço na construção e inserção do aluno no } \\
\text { contexto da sociedade, tendo o objetivo de auxiliar na formação de cidadão crítico no } \\
\text { exercício de sua cidadania. }\end{array}$ \\
\hline Geografia Brasileira & $\begin{array}{l}\text { Traz a concepção de que o espaço é entendido como um organismo vivo, não como } \\
\text { uma estrutura inerte, não sendo passível de ser abordado, mas como fruto de uma } \\
\text { dinâmica social e na busca da complexidade dos processos sociais que atuam na } \\
\text { configuração territorial brasileira. }\end{array}$ \\
\hline $\begin{array}{ll}\text { Atividades } & \text { de } \\
\text { Voluntariado } & \end{array}$ & $\begin{array}{l}\text { Busca oferecer auxílio aos menos favorecidos para um equilíbrio de classes sociais, } \\
\text { sendo realizado em entidades públicas que não visem lucro, objetivando instigar tal } \\
\text { trabalho como forma de atuação e benefícios da autoestima própria e aos atendidos. }\end{array}$ \\
\hline
\end{tabular}

Fonte: Unoesc Chapecó, 2011. 
Atividades interdisciplinares e integração social

$\mathrm{Na}$ busca das relações entre os componentes da matriz curricular e as atividades práticas, foram realizadas atividades interdisciplinares juntamente com alguns cursos de graduação da instituição: Educação Física, Psicologia, Direito e Sistemas de Informação. Destacam-se:

- História de vida: os alunos da UMIC oferecem seu depoimento referente à sua trajetória de vida, com intuito de possibilitar a troca de conhecimentos e informações entre as faixas etárias.

- Direito de olho na cidadania: o curso de Direito, por meio do grupo de pesquisa em direitos fundamentais, socializou suas experiências e fomentou para os idosos o exercício autônomo dos direitos fundamentais a partir do esclarecimento.

- Junto com o curso de Educação Física, os idosos participaram de campanhas como: doação de sangue junto no Hemosc de Chapecó; campanha de combate ao câncer de mama realizada juntamente com a Rede Feminina de Combate ao Câncer de Chapecó; resgate de brinquedos e brincadeiras histórico culturais junto ao Laboratório Lúdico do curso.

- Ação J.A. Operação Cidadania: projeto da RBS TV e inúmeras entidades beneficentes de Chapecó, com a proposta que os idosos ensinassem às crianças, jovens e adultos a confecção de bonecas de pano e colchas de retalhos.

- Conversação com os professores: se desenvolve a partir das ferramentas disponibilizadas em cada disciplina na concepção de trabalhos voltados à interdisciplinaridade.

- Integração de alunos veteranos e egressos: ocorre por meio de palestras realizadas na Cidade do Idoso de Chapecó - um espaço disponibilizado pela Prefeitura Municipal de Chapecó especialmente preparado para os idosos, com exposição de fotografias de todas as atividades realizadas na UMIC, servindo para integrar o público e repassar informações.

- Exposição de artes no Museu de Chapecó: por meio de trabalhos realizados nas aulas de artes, com a técnica de mosaico, que possibilita ao aluno desenvolver a percepção, concentração, coordenação motora, conhecimento teórico, prático e criatividade; ainda, a exposição de fotografias no Museu de Chapecó, com a temática "Feliz Idade", retratando os momentos que refletiam felicidade e alegria dos idosos a partir das aulas de fotografia. 
- Prática de atividades físicas como: musculação, caminhadas orientadas, relaxamentos, dança, possibilitam conhecer a teoria e a prática, além das dinâmicas como jogos integrativos realizados juntamente com o curso de Educação Física da Unoesc Chapecó; ainda, destacam-se as atividades de meditação e terapias coletivas que têm a intenção de proporcionar a integração entre o grupo e autoconhecimento.

- Coral UMIC Unoesc Chapecó: desenvolvido em parceria com a Associação Coral de Chapecó com a pretensão de desenvolver a cultura e a arte, possibilitando a inclusão do idoso a partir das apresentações na comunidade.

- Cinema na Unoesc: as apresentações tiveram o intuito de desenvolver a capacidade de reflexão e ampliar a visão dos alunos sobre a realidade, trazendo à tona histórias vividas, emocionantes e de superação, momento em que expuseram dores, alegrias e experiências.

- Incentivo à leitura: envolveu atividades como o resgate de obras que estavam em casa para a troca com os colegas e doação à biblioteca, exposição de fotografias históricas de Chapecó no corredor principal da instituição, com o intuito de socializar com os acadêmicos da graduação, professores e colaboradores; ainda, a exposição do "varal de poesias" com tema "a história de Chapecó", exposição dos trabalhos de artes e discussão de textos para estimular a leitura no espaço da biblioteca da Unoesc Chapecó.

- Participação em eventos multidisciplinares como: Seminário Estadual de Envelhecimento Ativo, a Conferência Regional de Inovação e Empreendedorismo, o Seminário da Região Oeste Catarinense sobre inclusão se pessoas com deficiência no mercado de trabalho; visitação aos pontos históricos regionais, aprendizagem de técnicas de desenho, exposição do material produzido nas disciplinas em sala de aula, além de atividades de expressão corporal, por meio de elaboração e apresentação de peça teatral com temas relacionados aos conteúdos abordados em aula, sempre valorizando a educação, a cultura e o lazer dos idosos.

\section{Contribuição para a RSU}

Ao relatar as experiências vividas na UMIC, um projeto de extensão, evidencia-se a eficiência e eficácia desse projeto em relação aos objetivos originais - "proporcionar aos idosos conhecimentos que agreguem valores para melhorar a sua qualidade de vida e que obtenham envelhecimento saudável; ampliar conhecimentos nas diversas áreas; promover ações quais as garantam o bem estar biopsicossocial; oportunizar espaços para prática de esportes, atividades culturais e ampliação dos conhecimentos" (UNOESC, 2011). 
Uma demonstração clara da integração social são as atividades desenvolvidas em sala de aula entre os componentes da matriz curricular e com atividades desenvolvidas de forma extracurricular, permitindo além da consolidação efetiva do processo interdisciplinar, uma simbiose de interlocução com os cursos de graduação, algo que para os idosos, em sua ampla maioria, se traduz em algo inovador para suas vidas. Velho (2010) consolida a visão interdisciplinar destacando tratar-se de um novo paradigma científico, instaurado em meados do século XX que ultrapassaria os limites da atividade científica, tornando-se um dos focos da cultura geral e do senso-comum de um novo tempo que buscava soluções para problemas concretos que envolviam acadêmicos e não acadêmicos. Silva (2012) também afirma que a interdisciplinaridade teve forte apelo acadêmico de professores e estudantes que se estabelece na década de 1960 na Europa com grande ênfase na França e Itália, em busca de uma nova proposta educacional.

De forma abrangente, as atividades permearam projetos sociais e vivências educativas e integrativas não contempladas na matriz curricular do curso. Os processos de ensino e aprendizagem nos momentos interdisciplinares colaboraram para a integração com a comunidade acadêmica e com a sociedade, fortalecendo o espaço da pesquisa e motivando os alunos a continuarem seus estudos. Velho (2010) e Silva (2012), acrescentam que essa é uma temática que transita pela comunidade profissional e acadêmica com a finalidade de resolver problemas cotidianos, entrelaçando ideias que possibilitam novos rumos para as práticas profissionais e da construção de conhecimento acadêmico.

Assim, a UNOESC apresenta sua intensa e necessária relação com a Responsabilidade Social, visto perceber na sua missão elementos como "formar pessoas, produzir conhecimento e oferecer extensão e serviços, promovendo o desenvolvimento institucional e regional" (UNOESC, 2013). Alinhado com essa perspectiva, no seu PDI - Plano de Desenvolvimento Institucional (2013-2017) é destaque que a “(...) a responsabilidade social da instituição, onde a função social da Unoesc extrapola a sua missão de formar pessoas, produzir e difundir o conhecimento". Seu caráter comunitário indica que sua interação com a sociedade permeia a vida da comunidade regional, compõe o tecido social presente no cotidiano de famílias, empresas e organizações. Complementarmente, sua visão de futuro ampara e valoriza “(...) a excelência acadêmica e atuação como agente de desenvolvimento regional." Todos estes elementos são amparados por valores como: "ética, no humanismo, na cooperação, no comprometimento, na responsabilidade social, na inovação e na solidez". (UNOESC, 2013).

A partir dessas ponderações, percebe-se que projetos de extensão como a UMIC, que oferecem formação além dos limites da sala de aula, transitando por inúmeras práticas interdisciplinares, com um público idoso, deveras restrito de oportunidades de integração social e reintegração social, que há muito não aventavam a possibilidade de inter-relação com pares, com jovens, com professores de múltiplas formações, de contato com um meio saudável de vida e de saúde, justificam sua operação como forma consolidada de demonstrar sua contribuição para a UNOESC no que tange à Responsabilidade Social Universitária.

\begin{tabular}{l|l|l|l|l|l|l} 
(C) Rev. Inter. Educ. Sup. & Campinas, SP & v.2 & n.1 & p.191-213 & jan./abr. 2016 & ISSN 2446-9424
\end{tabular}


Evidencia-se, portanto, que a UNOESC, por meio do seu Campus de Chapecó, ao estimular projetos com a UMIC, cumpre e operacionaliza seu papel institucional de indissociabilidade entre o ensino, pesquisa e extensão, conforme previsto na Constituição brasileira de 1988 em seu artigo 207, “(...) obedecerão ao princípio da indissociabilidade entre ensino, pesquisa e extensão", princípio reforçado por Moita e Andrade (2013), Andes (1982), Pucci (1991) e Raye (2003).

Nesse horizonte, este texto demonstra a atenção empreendida pela UNOESC com a extensão, percebendo ser este um dos caminhos que visa o fortalecimento da relação universidade e sociedade priorizando a superação das condições de desigualdade e exclusão existentes, por meio de projetos sociais, socializa seu conhecimento e disponibiliza serviços, exercendo sua responsabilidade social, cumprindo sua missão de melhorar a vida dos cidadãos (SERRANO, 2013; JEZINE, 2004; RAYS, 2003).

Ao considerarmos que a Responsabilidade Social Universitária, segundo a visão compartilhada por Kliksberg (2006), Vallaeys (2006), Carrizo (2006) apresenta como características essenciais a promoção social com princípios éticos, sustentáveis, justos e de desenvolvimento social, alicerçando o processo de ensino e aprendizagem para a transmissão de saberes com vistas à formação de cidadãos também responsáveis socialmente, contribuindo para a diminuição das desigualdades sociais e de oportunidades, associadas diretamente ao desenvolvimento humano, fica a percepção que atividades de extensão como a UMIC contribuem sobremaneira dar conta desse processo.

Complementarmente, é possível evidenciar que além do processo interdisciplinar existente, Velho (2010) e Silva (2012) constatam fortes indícios que projetos dessa natureza contribuem significativamente para a consolidação da dimensão 3 Responsabilidade Social da Instituição de Ensino Superior (IES), prevista no SINAES (2004). Neste sentido, o projeto de Extensão UMIC apresenta estímulos que devolvem em certa medida a autonomia sobre suas vidas para o idoso, permitindo melhorias em relação à gestão de uma vida mais saudável, reintegrando-os ao ambiente familiar e à sociedade, oferecendo acesso a informações e orientações acerca de seus direitos e deveres como cidadãos, respeitando regras de convivência, por meio de disciplinas teóricas direcionadas à legislação. Além disso, viabiliza informações referentes à nutrição de forma a obter conhecimentos para uma alimentação saudável, preparação da alimentação e arrumação do espaço, estimulando os cuidados com a saúde através de oficinas educativas, proporcionando o desenvolvimento criativo com inserção em oficinas relacionadas a artes, com visitação a pontos históricos regionais, aprendizagem de técnicas de desenho, exposição do material produzido nas disciplinas em sala de aula. Atividades de expressão corporal são oferecidas por meio de elaboração e apresentação de peça teatral com temas relacionados aos conteúdos trabalhados em aula, sempre valorizando a educação, a cultura e o lazer dos idosos, para que as atividades não se tornem uma obrigação, mas algo que ofereça mais qualidade em suas vidas. Elementos 
preponderantes para a consolidação da RSU com os quais Kliksberg (2006), Vallaeys (2006) e Carrizo (2006) compactuam.

\section{Considerações finais}

A constatação verificada no artigo 207 da Constituição Federal de 1988 que dispõe sobre o princípio da "[...] princípio da indissociabilidade entre ensino, pesquisa e extensão", aliada ao necessário cumprimento do que dispõe o Eixo 2, Desenvolvimento Institucional e respectivas Dimensões 1 e 3: Missão e o Plano de Desenvolvimento Institucional (PDI) e a Responsabilidade Social da Instituição, previsto no SINAES (2004), acenam para um olhar mais pragmático das Instituições de Ensino Superior (IES), em especial as Universidades com características comunitárias, no que tange às ações empreendidas para a efetiva contribuição para o Desenvolvimento Social e por conseguinte o cumprimento deste preceito legal.

Evidencia-se que a consolidação da RSU passa necessariamente pelo olhar atento da gestão dos princípios da indissociabilidae entre o ensino, pesquisa e extensão, elementos constitutivos e findos das universidades, que quando não executados adequadamente, contrariam e violam o preceito legal (ANDES, 1982; PUCCI, 1991; MOITA e ANDRADE, 2013). Complementarmente, restou claro que projetos de Extensão universitária de cunho interdisciplinar, e em certa medida transdisciplinar, como a UMIC, apresentam forte contribuição para a consolidação da RSU, observando a gama de atividades desenvolvidas para uma população de idosos com mais de 60 anos, que valoriza sobremaneira a promoção social com princípios éticos, sustentáveis, de justiça, de formação cidadã e responsáveis socialmente, de conscientização ambiental, priorizando o desenvolvimento humano saudável e social, elementos apregoados por Kliksberg (2006), Vallaeys (2006) e Carrizo (2006) Calderón (2006). Trata-se de reflexos formativos, empunhados pelo trânsito em diversas áreas do conhecimento, que a UMIC proporciona.

Também ficou claro que, isoladamente, projetos de Extensão universitária como a UMIC não atingem na plenitude o compromisso social das Universidades, pontualmente as comunitárias lócus deste estudo, se tratam de iniciativas válidas e robustas pela capacidade de envolvimento e trabalho concentrado nos princípios basilares da RSU, mas demonstram certo distanciamento em alguns aspectos transversais no que se refere a princípios e valores que oferecem suporte à gestão universitária e consolidação da RSU segundo a visão de Calderón (2006), Carrizo (2006) e Vallaeys (2006). Complementarmente, evoca-se o princípio da indissociabilidade entre o ensino, a pesquisa e a extensão, que indistintamente devem incorporar ações que promovam Desenvolvimento Social. 


\section{Referências}

APPOLINÁRIO, F. Dicionário de metodologia científica: um guia para a produção do conhecimento científico. São Paulo, Atlas, 2009.

ASHLEY, Patrícia Almeida, FERREIRA, Roberto; REIS, Helvécio Luiz. Sistema Nacional de Avaliação da Educação Superior: Oportunidades para a responsabilidade social na gestão estratégica de instituições de ensino superior. Revistas Gerenciais, São Paulo, v. 5, p. 23-35, 2006.

BANCO MUNDIAL. Public sector roles in strengthening corporate social responsibility: a baseline study. Washington, 2002. Disponível em: Acessado em: 19/10/2015.

BRASIL. Constituição da República Federativa do Brasil. Brasília, DF: Senado Federal, 1988.

BRASIL. Lei no 10.861, de 14 de abril de 2004. Institui o Sistema Nacional de Avaliação da Educação Superior - SINAES e dá outras providências. Diário Oficial da União, Brasília-DF, 15 abr. 2004.

CADERNOS DA ANDES. Proposta das AD's e da ANDES para a Universidade Brasileira. Juiz de Fora, n. 2, 1982.

CALDERÓN, Adolfo Ignácio. Universidades mercantis: a institucionalização do mercado universitário em questão. São Paulo em Perspectiva, São Paulo, v. 14, n. 1, 2000.

CARRIZO, Luís. Conhecimento e responsabilidade social: ameaças e desafios para a universidade transdisciplinar. Estudos, Brasília-DF, ano 24, n. 36, p. 76-89, mar. 2006.

CERVO, A. L.; BERVIAN, P. A. Metodologia Científica. $5^{\text {a }}$ ed. São Paulo: Prentice Hall, 2002.

DÁVILA, Paulo G. S et.al. Avaliação da proposta de construção de um currículo interdisciplinar numa escola técnica de saúde. Trabalho e Educação v. 6, n. 1, p 169-193, mar./jun. 2008.

DRUCKER, Peter F. O melhor de Peter Drucker: A administração. São Paulo: Nobel, 2009.

FRIEDMAN, M. The social responsibility of business is to increase its profits. New York Times Magazine, setembro, 1970.

GADOTTI, Moacir. Interdisciplinaridade: atitude e método. São Paulo: Instituto Paulo Freire. Disponível: <www.paulofreire.org>. Acesso em: 20 Nov. 2013.

GODOY, A. S. Pesquisa qualitativa: tipos fundamentais. Revista Administração de Empresas. 1995, v.35, n.3, p. 20-29. 
HERRERA, Alma. Responsabilidade social das universidades. In: GUNI. Educação superior em tempos de transformação: novas dinâmicas para a responsabilidade social. Porto Alegre: EDIPUCRS, 2009, p. 41-42.

JEZINE, Edineide. As Práticas Curriculares e a Extensão Universitária. Anais do $2^{\mathbf{0}}$ Congresso Brasileiro de Extensão Universitária, Belo Horizonte, 2004.

JIMÉNEZ DE LA JARA, Mónica et al. Responsabilidade universitária: uma experiência inovadora na América Latina. Estudos, Brasília-DF, ano 24, n. 36, p. 57-73, mar. 2006.

KLIKSBERG, Bernardo. A ética e a responsabilidade social da universidade. Estudos. Revista da Associação Brasileira de Mantenedores de Ensino Superior. Brasília-DF, Ano 24, n. 36, mar. p. 23-25, 2006.

MACÊDO, Arthur Roquete de. O papel social da universidade. Estudos. Revista da Associação Brasileira de Mantenedores de Ensino Superior. Brasília-DF, Ano 23, n. 34, abril, p. 7-12, 2004.

MAZINI FILHO, Mauro L. et. al. Atividade física e envelhecimento humano: a busca pelo envelhecimento saudável. Revista Brasileira de Ciências de Envelhecimento Humano. Passo Fundo, RS, v.7, n.1, p.97, 2010.

MOITA, Filomena Maria Gonçalves da Silva Cordeiro. ANDRADE, Fernando Cézar Bezerra de. A indissociabilidade entre ensino, pesquisa e extensão: o caso do estágio de docência na pós-graduação. Revista Olhar de Professor, v. 16, n. 2 (2013).

MORIN, Edgar. Estamos em un Titanic? In: KLIKSBERG, Bernardo. Ética y desarrollo: la relación marginada. Buenos Aires: El Ateneo, 2002, p. 143-148.

NUNES, Ana Lucia de Paula Ferreira; SILVA, Maria Batista da Cruz. A extensão universitária no ensino superior e a sociedade. Revista Mal Estar e Sociedade, ano IV. Barcelona - julho/dezembro, p. 119-133, 2011.

PÁDUA, E. M. M. Metodologia de pesquisa: abordagem teórico-prática. Campinas: Papirus, 2004.

PAOLI, M. C. Empresas e responsabilidade social: os enredamentos da cidadania no Brasil. In: SANTOS, B. S. (Org.) Democratizar a democracia: os caminhos da democracia participativa. Rio de Janeiro: Civilização Brasileira, 2002.

PERNALETE, Mariela Torres; ORTEGA, Miriam Trápaga. Responsabilidad Social de la Universidad: retos y perspectivas. Buenos Aires: Paidós, 2010.

PUCCI, Bruno. A indissociabilidade entre Ensino Pesquisa e Extensão. Impulso, Piracicaba, p. 33- 42, 1991.

RAYS, Oswaldo Alonso. Ensino Pesquisa Extensão: notas para pensar a indissociabilidade. Cadernos de Educação Especial/Universidade Federal de Santa Maria. Departamento de 
Educação Especial/LAPEDOC. Vol. 1 - No 19 (2002) - 114 p. Santa Maria. Edição: № 21. 2003.

REZENDE, Flavia e QUEIROZ, Glória R.P.C. Apropriação discursiva do tema interdisciplinaridade por professores e licenciados em fórum eletrônico. Ciência \& Educação, v. 15, n. 3, p. 459-478, 2009.

SANTOS, Boaventura de Sousa. Pela mão de Alice: o social e o político na pósmodernidade. São Paulo: Cortez Editora, 1995.

SERRANO, Rossana Maria Souto Maior. Conceitos de extensão universitária: um diálogo com Paulo Freire. https://scholar.google.com.br/scholar?hl=pt-

$\mathrm{BR} \& \mathrm{q}=$ Conceitos+de+extens $\% \mathrm{C} 3 \% \mathrm{~A} 3 \mathrm{o}+$ universit $\% \mathrm{C} 3 \% \mathrm{~A} 1 \mathrm{ria} \% 3 \mathrm{~A}+\mathrm{um}+\mathrm{di} \% \mathrm{C} 3 \% \mathrm{~A} 1 \log \mathrm{o}+$ com+Paulo+Freire\&btnG=\&lr=. Acesso 20 março 2016.

SILVA, Jonathas Luiz Carvalho. Das concepções disciplinares nas Ciências de Informação e/ou de suas configurações epistemológicas: o desiderato percepcionado da interdisciplinaridade. Investigación Bibliotecológica, v.27, n.59, enero. Abril, México, p. 67-92, 2013.

SILVA, Wagner Rodrigues. Seleção textual no ensino interdisciplinar por projeto. Revista Brasileira Linguística Aplicada, Belo Horizonte, v.9, n.1, p. 17-39, 2009.

THIESEN, Juares da Silva; A interdisciplinaridade como um movimento articulador no processo ensino- aprendizagem. Udesc. São José SC, Departamento de Educação, Revista Brasileira de Educação v. 13, n. 39 set./dez. 2008.

TRIPP, David. Pesquisa-ação: uma introdução metodológica. Educação e Pesquisa. Universidade de Murdoch. São Paulo, v. 31, n. 3, p. 443-466, set./dez. 2005.

UNOESC. Plano de Desenvolvimento Institucional da Unoesc. Joaçaba: Unoesc, 2013.

UNOESC. Projeto de Extensão Universidade da Melhor Idade de Chapecó- UMIC. Unoesc Campus de Chapecó, 2011.

VALLAYES, F. Que significa responsabilidade social universitária? Estudos. Revista da Associação Brasileira de Mantenedores de Ensino Superior. Brasília-DF, ano 24. no 36. Junho, pp.35-56, 2006.

VASCONCELOS, Flávio Carvalho de. Estratégias acadêmicas, interdisciplinaridade e os requisitos organizacionais da produção de conhecimento. Ver. Administração Pública. RJ, 46 (6): 1429-35, nov./dez. 2012.

WAGENBERG, Alan. A urgência da responsabilidade social universitária. Estudos, Brasília, DF, ano 24, n. 36, mar. p. 27-34, 2006. 